\title{
Aboriginal art and oral history in the colonial narrative
}

\section{Zachary Blue}

University of Technology Sydney, Faculty of Arts and Social Sciences, PO Box 123, Ultimo NSW 2017, Australia. zachary.r.blue@student.uts.edu.au

DOI: https://doi.org/10.5130/nesais.v4i1.1533

\begin{abstract}
Eurocentric conceptions of Indigenous history have long dominated the conversation around what constitutes 'legitimate' Aboriginality. This essay examines the hyper-scrutiny Aboriginal art and oral history forms are subject to, as well as the continual omission and manipulation of Aboriginal history as a reflection of the ongoing colonial process.
\end{abstract}

Keywords: oral history; Indigenous art; the colonial gaze

\begin{abstract}
Aboriginal historical practices form subversive discourses that undermine the Eurocentric conception of the past. Both traditional art history and oral history principles have undergone challenges in processing Aboriginal history in the corresponding frameworks. This essay will focus on the hyperscrutiny Aboriginal art and oral history forms are subject to, and the continual omission and manipulation of Aboriginal history as a reflection of the ongoing colonial process. Through a close study of art and oral history theory in Western canon, this essay will explore the subversive and genreexpanding nature of Aboriginal history, both enabling and criticising our understanding and conceptualisation of the past and 'legitimate' histories. As such, this essay will focus not on specific examples of oral and art history, but rather the discourses surrounding each principle and their use as a vector of historical control.
\end{abstract}

Art history theory and the framework by which pieces of art are legitimised as history, and hence valid contributions to the past, are rooted in Eurocentric understandings of art. Whilst the discipline of art history is slowly becoming democratised in its inclusion of non-conventional art forms as history, the treatment of Aboriginal art demonstrates a conceiving of non-conventional art forms as inauthentic, thus reinforcing notions of conventional, Western art as 'legitimate' history. As Coleman reiterates, "the idea of authenticity is not merely an ethnocentric reflection of the modern discourse of fine art; it is also a piece of ideology, an unintended justification of a continuing exploitative power relation" (Coleman 2001, p. 386). This "exploitative power relation" is a core facet in the silencing and marginalising of Aboriginal historical forms, particularly in relation to art history and the hyper- 
scrutiny Aboriginal art receives. This hyper-scrutiny refers to the application of Coleman's notion of exploitative power and the channelling of Aboriginal art through Eurocentric concepts.

Coleman outlines the application of four art theory principles to Aboriginal art as a criterion for authenticity. The focus of this criterion is the context in which the art is produced, and if it can be considered 'traditional'. Aboriginal art which is sold is critiqued as being "not spiritually motivated but produced for sale and therefore not traditionally Aboriginal" (Coleman 2001, p. 385). At this point it is important to note that the concept of what is 'traditionally Aboriginal' used by art historians is one developed as per the observations of European historians, and yet has been galvanised as the standard of 'Aboriginal legitimacy'. Furthermore, the use of acrylics, canvas, or "any other medium that is not traditional" is considered to render the art inauthentic as it veers from tradition (Coleman 2001, p. 385). The last criteria to which Aboriginal art is held when defining its legitimacy is the heritage of the composer. Those who were deemed to be not of Aboriginal descent were not considered legitimate proprietors of the art form. All these criteria rely on a static and stagnant conception of tradition. They subject Aboriginal cultural and historical products to a white reference for Aboriginality in an attempt to discount legitimate cultural products that may challenge what is accepted as art history as well as the colonial narrative. As Coleman states, this criterion employs a "false understanding of the nature of authenticity as tradition", whereby "tradition cannot be a criterion of authenticity, according to Shiner, because there is a constant cultural and economic exchange between societies" (Coleman 2001, p. 386).

To fully understand the power dynamic and manipulation of the historical narrative in relation to Aboriginal art, we must also examine what art history does deem permissible and historically accurate. According to Mattos, during the 'art history crisis' of the $20^{\text {th }}$ century characterised by a shift away from Renaissance and Enlightenment art as traditional historical forms, "many artists who looked for fresh ideas turned to non-European traditions for inspiration" (Mattos 2014, p. 259). "African masks, Japanese art, and indigenous artefacts" were all incorporated into art narratives as a representation of indigenous populations, "however it is clear now that these non-European traditions were not perceived in their own terms to produce what could have been a genuine artistic exchange" (Mattos 2014, p. 259). Paradoxically, traditional Indigenous art forms were appropriated by Western painters to add authenticity to their representations of Indigenous peoples. These techniques "were evoked in strictly European terms, as a "radical other" (Mattos 2014, p. 259), usually to support the dominant view of Aboriginal peoples as uncivilised and to "implant their own images of the colonial process" (Morris 1992, p. 73). Elements of Aboriginal art were repurposed and appropriated to suit white colonial sensibilities while simultaneously being used to criticise and delegitimise the Aboriginal production of art. Of those pieces composed by Aboriginal artists that are deemed 'legitimate' by art theory, or "the representations of the acrylic paintings offered by whites", they "have primarily constructed a permissible Aboriginal culture, that is, a representation that meets the approval of the dominant white society's notions of "common humanity"' (Myers 1991, p. 35). This "colonial discourse masquerading as history" demonstrates the malleable nature of history and the production of a tailored past manufactured to fit a colonialist narrative (Morris 1989, p. 6).

The continual production of Aboriginal art represents a challenge to the dominant colonial narrative in both art history and the representation of Aboriginal peoples. This production of Aboriginal art seeks 
to fill the lacuna surrounding Aboriginal perspectives and encourages the acceptance of their art as a form of storytelling and history. As such,

...the production, circulation, and consumption of these objects constitutes an important dimension of self-production of Aboriginal people and of the processes of 'representing culture', significant in what Appadurai and Breckinridge (1988:1) have described as the 'global cultural ecumene'." (Myers 1991, p. 28)

The establishment of this vehicle of cultural 'self-production' subverts the power frameworks of traditional art theory, whereby the Aboriginal art industry is functioning outside of the ideals of conventional legitimacy. This production of art has both manifested a challenge of colonial representations of Aboriginal people and offered a vehicle for self-determination, as "art production is the main source of commercial income for many remote communities with art centres," where "between 2008 and 2012, remote Indigenous art centres generated around \$53 million in art sales, with $\$ 30$ million paid to artists” (Australian Council for the Arts 2015, p. 31).

Popularity has afforded its own sense of legitimacy to Aboriginal art and demonstrated its communicative power. In this context we may also characterise the use of Western painting materials, such as the acrylic art and canvas mentioned prior, as a retaliation against and reframing of colonial materials. Reynolds argues the use of European farming tools such as iron axes forms a method of survival and manipulation of colonial circumstances by Aboriginal peoples, and the repurposing of Western artistic materials for the production of independent Aboriginal materials can be viewed in the same vein (Reynolds 1990, p. 8). This cultural strategy of survival directly influences our understanding of the past by offering conflicting accounts to the colonial narrative. However, art theory and its criticality of Aboriginal art continue to perpetuate preconceived notions of Aboriginality. Whilst some art theorists recognise "it is time to start to be suspicious of monolithic identities inscribed in concepts such as the "national' and 'nationality"' in colonial art contexts, the root of art theory in Eurocentric ideology continues to "work here as a real power weapon that secures the control of the discipline for Western art historians" (Mattos 2014, p. 260).

Aboriginal oral history traditions have faced similar criticism within the hegemonic paradigms of oral history. Oral history grants access to a myriad of sources that provide "access to undocumented experience... and the "hidden histories' of people on the margins" (Thomson 1998, p. 587). Yet, what is referred to as the subjective nature of oral histories and "the use of memories as historical evidence" has long draw criticism in historical theory (Thomson 1998, p. 584). Since being described as a practice in "the world of image, selective memory, later overlays and utter subjectivity" by Australian historian Patrick O'Farrell in the late 1970s, oral history has come to conceive of its inherent subjectivity as a positive (Thomson 1998, p. 585). Modern oral history focuses on personal experiences of history in an attempt to garner the social meanings of past events. Through a multitude of oral histories, one may form an image of community identity, as well as critique inaccuracies or differences in the individual recited histories. Yet, there are still doubts of its integrity within the discipline. Aboriginal oral traditions directly suffered from the early conception of oral history as invalid. The epistemological attitudes employed by Western historians throughout the 1900s discounted the validity of Aboriginal oral history and contributed to the current lacuna of Aboriginal experiences and narratives of dispossession. Even when oral history recording techniques were 
employed, the Eurocentric nature of the interview process was not applicable to the Aboriginal experience, as "interview techniques developed in the West may be incompatible with Indigenous systems and relations of communication" (Thomson 1998, p. 582). These boundaries to the dissemination of Aboriginal history further reinforced colonial narratives and formed just one facet of the conscious denial of Aboriginal experiences.

Yet, much like art theory, oral history archetypes are becoming increasingly democratic with a shift towards the acceptance of oral history as a legitimate form of historical data. This widening of parameters has opened the door for counter-narratives and subversive histories to emerge in traditional Western canon. As Shoemaker asserts, "when compared with white historical literature, Aboriginal historical novels and plays frequently offer strikingly different interpretations of past events-and do this in a stylistically unique fashion" (Shoemaker 2004, p. 132). This explicitly revisionist history embodies how the democratisation of oral history has enabled Aboriginal authors to communicate knowledge and narratives of dispossession previously disregarded by some historians. The ability of Aboriginal authors and historians to access "the huge wellspring of the oral tradition - a source which is as rich as it is foreign to European culture," differentiates and empowers Aboriginal history in the portrayal of conflicting realities of colonisation (Shoemaker 2004, p. 132). The exclusion of oral traditions such as song cycles formed just one part of the conscious decision of Western history to omit the experiences of Aboriginal peoples. Storytellers and orators were unable to "seek a simple recognition - the recognition of the truth of who we are" (Yunupingu 2016, para. 36). Western historians instead sought to create the myth of the colonial experience, whereby the only sources that were granted a sense of 'historical significance' where those that reflected the progress of colonialism (Nugent 2008, p. 198). Whilst the historical omission of Aboriginal experiences has contributed to the formation of a one-sided historical discourse, it has also added an emphasis to the plight of Aboriginal revisionist history. As Shoemaker argues, revisionist history is directly challenging established notions of Aboriginality, through the "usage of the techniques of the venerable Aboriginal oral tradition; through the endeavour to foster a sense of contemporary Aboriginal pride in leaders and heroes of the Black Australian past; and through reinterpretation-often vividly symbolic - of Australian interracial history" (Shoemaker 2004, p. 126).

Through an examination of both art and oral history frameworks and the contributions Aboriginal historical forms have made to the respective disciplines, we can clearly see the subversive nature of Aboriginal historical discourse. A challenging of the conception of legitimacy in art theory has resulted in the utilisation of Aboriginal art as a vehicle for self-determination and cultural production that challenges colonial narratives of occupation. The popularity of these cultural products and the power of their message have defied the traditional archetypes of art history, emphasising the need for the continual expansion of the theory and the inclusion of Aboriginal art forms on their own terms. Similarly, the development of oral history as a respected historical discipline has enabled Aboriginal historians and authors to delve into the oral histories of their past to provide a personal and emotive narrative in opposition to formerly accepted accounts of history. The continual plurality of Australian history is only advanced by the contributions of Aboriginal art and oral history traditions, complimenting a revisionist history that seeks to mediate the past. 


\section{References}

Australian Council for the Arts, 2015, Arts Nation: An Overview of Australian Arts, 2015 edition, Sydney, Australia.

Coleman, E.B. 2001, “Aboriginal Painting: Identity and Authenticity", The Journal of Aesthetics and Art Criticism, vol. 59, pp. 385-402. https://doi.org/10.1111/0021-8529.00040

Mattos, C. 2014, "WHITHER ART HISTORY?: Geography, Art Theory, and New Perspectives for an Inclusive Art History”, The Art Bulletin, vol. 96, pp. 259-264.

https://doi.org/10.1080/00043079.2014.889511

Myers, F. 1991, "Representing Culture: The Production of Discourse(s) for Aboriginal Acrylic Paintings", Cultural Anthropology, Vol. 6, pp. 26-62. https://doi.org/10.1525/can.1991.6.1.02a00020

Morris, B., 1989, 'Colonial Domination as a Process of Marginalisation' in Domesticating Resistance: the Dhan-Gadi Aborigines and the Australian state, Oxford, Berg., pp. 6-30.

Morris, B., 1992, 'Frontier colonialism as a Culture of Terror', in Power, Knowledge and Aborigines, Bundoora, Vic., La Trobe University Press in association with the National Centre for Australian Studies, Monash University, pp 72-87.

Nugent, M., 2008, 'The encounter between Captain Cook and Indigenous people at Botany Bay in 1770 reconsidered', in Veth, Sutton and Neale (eds) Strangers on the Shore: Early coastal Contacts in Australia, Canberra ACT, National Museum of Australia Press, pp 198-207.

Reynolds, H., 1990, The other side of the frontier: Aboriginal resistance to the European invasion of Australia, Ringwood, Vic, Penguin, pp 5-29.

Shoemaker, A. 2004, Black Words White Page: New Edition, ANU Press. https://doi.org/10.26530/OAPEN 458832

Thomson, A. 1998, "Fifty Years On: An international Perspective on Oral History", The Journal of American History, Vol. 85, pp. 581-595. https://doi.org/10.2307/2567753

Yunupingu. G., 2016, 'ROM WATANGU: The Law of The Land', The Monthly, Issue 124, July, Melbourne, Schwartz Publishing Pty. Ltd. 